\title{
Numerical analysis of the construction of Odelouca Dam using a Subloading Surface Soil Model
}

\author{
A.Brito, J.R. Maranha, L. Caldeira \& C. Pereira \\ Geotechnical Department
}

National Laboratory for Civil Engineering, Lisbon, Portugal

\begin{abstract}
Odelouca dam is an embankment dam, with $76 \mathrm{~m}$ height, recently constructed in the south of Portugal. It is zoned with a core consisting of colluvial and residual schist soil, and with soil-rockfill mixtures making up the shells (weathered schist with a significant fraction of coarse sized particles). This paper presents a numerical analysis of Odelouca dam construction. In this analysis the explicit finite difference program FLAC is used. An unconventional elastoplastic soil model, a Subloading Surface type model, implemented into the program, is used to model the embankment materials. The main results are compared with those obtained with the Modified Cam Clay Model. The model's constants and internal variables initial values are determined from a comprehensive testing programme carried out in the Civil Engineering National Laboratory $(L N E C)$ for the hydraulic and mechanical characterization of the materials used and a Subloading Surface type model with plastic anisotropy is used to model its behaviour. Computational results are then compared to the ones obtained from the dam's monitoring system during the construction stage.
\end{abstract}

\section{INTRODUCTION}

The use, due to economical and environmental reasons, of nontraditional materials, such as soil-rockfill mixtures, in the construction of earthworks, brings new challenges to dam engineering. Usually, this kind of material results from the disaggregation by mechanical means of rock masses (without explosives), and it can include some large sized particles (about $0.5 \mathrm{~m}$ or larger). The behaviour of these materials depends on the relative fractions of their constituents, becoming closer to a soil, when the fine fraction is prevalent with the coarser material scattered in it, or closer to a rockfill, when the coarser particles are in contact with each other with the fines occupying the spaces between them.

In order to understand the behaviour of this material, a testing and a numerical modelling program were implemented at the Civil Engineering National Laboratory $(L N E C)$ in Portugal. The materials used in the studies came from the shoulders and core of Odelouca Dam. This paper presents numerical analyses of laboratory tests and Odelouca Dam's construction. The material constants of the soil model used are determined from the testing programme for the hydraulic and mechanical characterization of the materials used. Computational results are then compared to the ones obtained from the dam monitoring system during the construction stage.

\section{GENERAL CHARACTERISTICS OF ODELOUCA DAM}

Odelouca dam is a zoned embankment dam, with $76 \mathrm{~m}$ of height, located in Algarve, in the south of Portugal. The crest of dam, $11 \mathrm{~m}$ wide, is approximately $415 \mathrm{~m}$ long.

Figure 1 shows the dam cross-section.

The reservoir created by Odelouca dam encompasses a $7.8 \mathrm{~km}^{2}$ area and has a $157 \mathrm{hm}^{3}$ capacity at the maximum water level. Most of this volume is intended for water supply with a small part used to irrigate the downstream fields.

The embankment materials include clayey soil, in the core, and weathered schist and greywacke (soilrockfill mixture), with a significant fraction of large sized particles, in the shells. The use of materials, extracted mainly from the reservoir area, minimize the negative environmental impacts. The upstream slope incorporates the cofferdam creating a $14 \mathrm{~m}$ wide berm. 


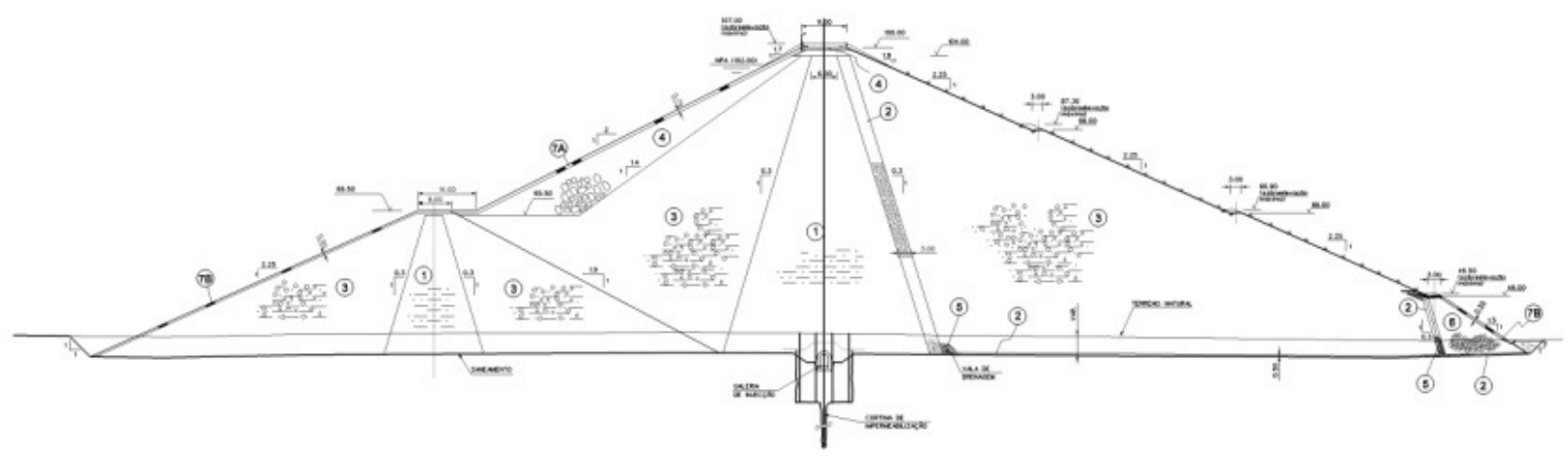

Figure 1. Odelouca dam cross-section.

\section{MODELING LABORATORY TESTS}

During the dam construction and afterwards, a comprehensive testing programme was carried out at $L N E C$ for the hydraulic and mechanical characterization of the materials used. One of first steps in the research programme consisted in finding a soil model able to adequately reproduce the tests performed in the clay material used in the core and in the soilrockfill material used in the shoulders.

In this analysis the explicit finite difference program FLAC was used. This is a two-dimensional program for geotechnical applications that allows the implementation of constitutive laws by the user.

\subsection{Elastoplastic Modified Cam Clay Model and Subloading Surface Model}

Due to its relative simplicity, the Modified Cam Clay Model (MCCM) (Schofield and Wroth, 1968) was first applied in modelling the tests performed on Odelouca dam's materials.

The MCCM is an elastoplastic model with hardening that incorporates, in a very simplified way, several fundamental aspects of soil behaviour.

This model assumes an associated flow rule making the plastic strain increments orthogonal to the yield surface in stress space.

Another feature of this model is that the hardening law is determined solely by the plastic volumetric strain increment.

The MCCM is already included in the program FLAC and was used to reproduce a set of four tests of the core's material used in Odelouca's dam construction. They were three undrained triaxial compression tests consolidated isotropically to three values of effective mean stress: 200,400 and $800 \mathrm{kPa}$ and a $\mathrm{K}_{0}$ consolidation test.

The MCCM is an elastoplastic model, so it exhibits a sharp transition in stiffness when going from elastic to elastoplastic behaviour. This proved to be a limitation of the model for the tested materials since they show a more gradual transition. Also, the materials tested presented an effective stress path with an inversion in direction which the MCCM was unable to reproduce. The model was, as well, unable to reproduce the $\mathrm{K}_{0}$ consolidation test.

Thus, the next step in the mathematical modelling was the search for a model capable of describing a more gradual and controlled transition between the elastic and elastoplastic behaviour, thereby enabling an improvement in the description of the observed behaviour. A family of models having this feature are the Subloading Surface Models.

The Subloading Surface Model, SSM, (Hashiguchi, 1989) is an unconventional elastoplastic model that extends elastoplasticity theory in such a way that the interior of the yield surface is not a purely elastic domain. Instead a plastic strain rate is induced by the rate of stress inside the yield surface. Thus, the conventional yield surface is, in this model, renamed the normal yield surface.

In this model the evolutionary process of the normal yield surface occurs by isotropic hardening and the surface containing the stress point, named Subloading Surface, is homothetic to the normal yield surface, requiring only an internal variable, R, defining its scale, as can be seen in Figure 2. The null stress state corresponds to $\mathrm{R}=0$, the sub-yield state to $0<\mathrm{R}<1$ and the normal yield state to $\mathrm{R}=1$. In isotropic conditions, $\eta_{a}$ is equal to zero.

The yield surface is defined by the implicit function:

$f(\sigma)=\left(\frac{q}{M}\right)^{2}+\bar{p}\left(\bar{p}-p_{c}\right)=0$

where $\bar{p}=p+\xi p_{c}$ and the subloading surface is described by:

$\bar{f}(\boldsymbol{\sigma})=f\left(\frac{1}{R} \boldsymbol{\sigma}\right)=f\left(\frac{1}{R} \bar{p}, \frac{1}{R} q\right)=0$

and the hardening law is given by:

$p_{c}=p_{c 0} \exp \left(\frac{\varepsilon_{v}^{p}}{\lambda^{*}-k^{*}}\right)$

The model requires five material constants: $\lambda^{*}, k^{*}$, $v, u$ and $M . \lambda^{*}$ and $k^{*}$, are determined so as to fit, respectively, the slope of the normal compression line and the line of elastic unloading/reloading obtained under isotropic stress conditions in a bi-logarithmic 
representation $(\ln v-\ln p)$, unlike the parameters $\lambda, k$ of the Cam Clay Model that are obtained in semilogarithmic representation $(v-\ln p)$. The material constant $u$ is determined so as to adjust the evolution of stiffness with strain in the transition from elastic to elastoplastic behaviour. The constant $\xi$ defines the effective tensile strength.

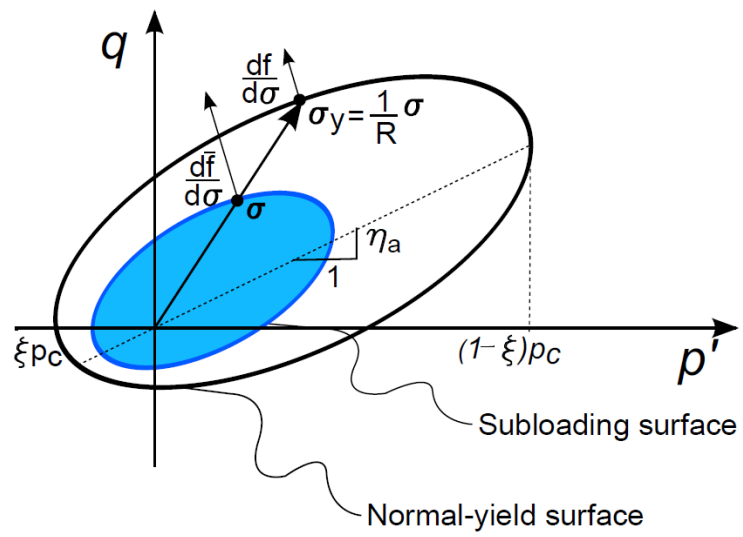

Figure 2. Normal yield and subloading surfaces.

The SSM was implemented in the program FLAC to reproduce the tests for the core materials of Odelouca Dam. Figure 3 and Figure 4 present the comparison between the results from the undrained triaxial tests and from the $\mathrm{K}_{0}$ consolidation test and those computed with the MCCM and with the SSM. The figures show, respectively, the deviatoric stress invariant, $q$, versus the axial strain, and the effective stress paths.

The Subloading Surface Model was able to reproduce adequately the undrained triaxial stress paths, even when a reversal in their direction occurs. However, the SSM was also incapable of reproducing the results of the $\mathrm{K}_{0}$ compression tests performed with the same material.

This is probably due to the fact that the samples were compacted (like it occurs in situ) which induces anisotropy of the material. Some experimental studies have shown that the yield surface of an anisotropically consolidated clay sample represented in the triaxial plane resembles a sheared ellipse oriented around the $\mathrm{K}_{0}$ consolidation line (Wong and Mitchell, 1975 and Davies and Newson, 1993). So, in order to try to adjust the results to the $\mathrm{K}_{0}$ consolidation line the next step consisted in introducing plastic anisotropic behaviour in the model.

\subsection{Anisotropic Subloading Surface Model}

Given the way an embankment dam is built, by a sequential placement of vertical compacted horizontal layers, it is expected that the resulting material presents plastic anisotropy (Maranha, 1997). This relevant feature was introduced in the SSM.

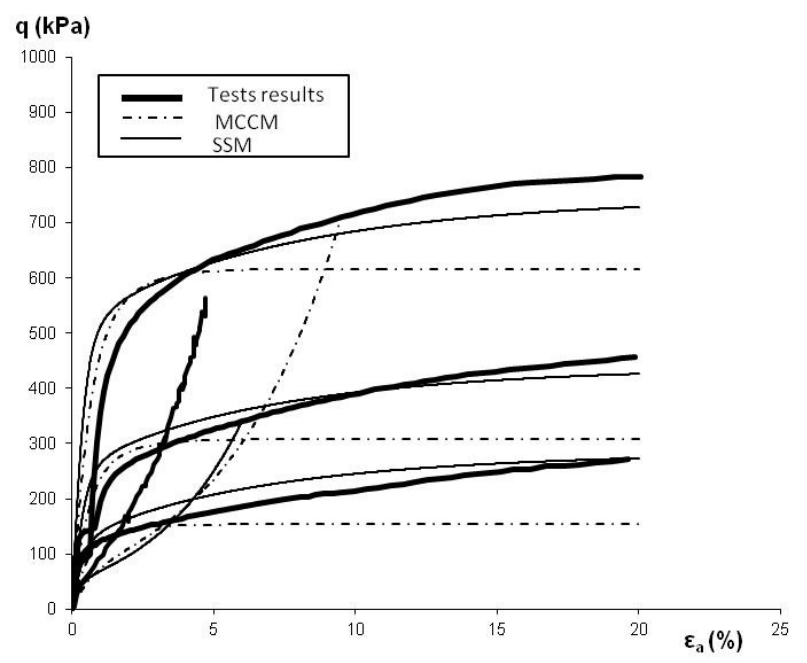

Figure 3. Deviatoric stress invariant vs axial strain for the experimental results, the SSM and the MCCM. The undrained triaxial tests with 200,400 and $800 \mathrm{kPa}$ isotropic consolidation, and the $\mathrm{K}_{0}$ test are represented.

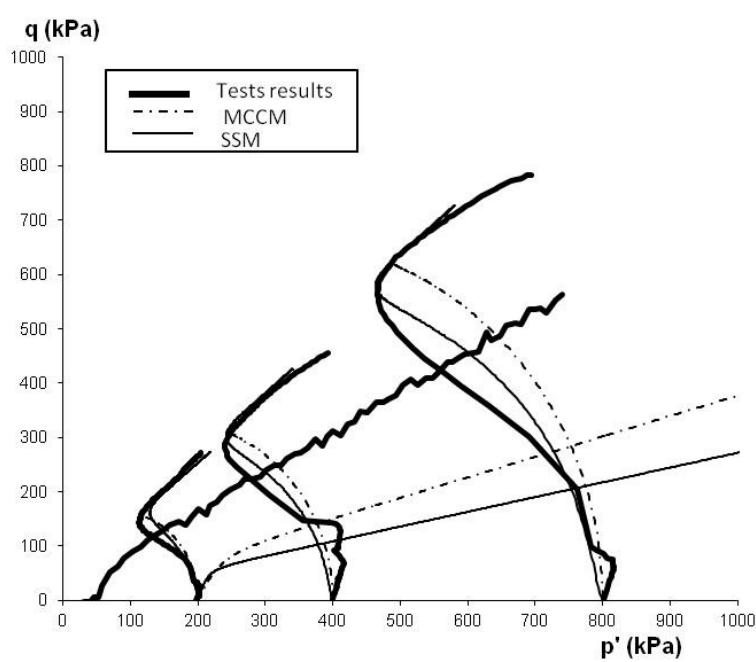

Figure 4. Effective stress paths for the experimental results, the SSM and the MCCM. The undrained triaxial tests with 200, 400 and $800 \mathrm{kPa}$ isotropic consolidation, and the $\mathrm{K}_{0}$ test are represented.

The resulting yield surface is now given by:

$f(\sigma)=\left(\frac{\bar{q}}{M(\bar{\theta})}\right)^{2}+\bar{p}\left(\bar{p}-p_{c}\right)=0$

where $\quad \bar{q}=\sqrt{\frac{3}{2} \bar{s}: \bar{s}}, \quad \bar{\theta}=\frac{1}{3} \sin ^{-1}\left(\frac{27 \operatorname{det} \bar{s}}{2 \bar{q}^{3}}\right)$,

$\bar{s}=s-p \boldsymbol{\beta}$ and $\eta_{a}=\frac{3}{2} \beta_{a}=\sqrt{\frac{3}{2}}\|\boldsymbol{\beta}\|$

and the anisotropic hardening law is:

$\dot{\boldsymbol{\beta}}=\dot{\gamma}\left\|\frac{d \bar{f}}{d \boldsymbol{\sigma}}\right\| \mu_{a}\left\langle\eta_{c}-\|\boldsymbol{\beta}\|\right\rangle\left(\boldsymbol{\beta}-\mu_{b} \frac{\bar{s}}{p}\right)$ 
where $\dot{\gamma}$ is the plastic multiplier, $\mu_{a}, \eta_{c}$ and $\mu_{b}$ are material constants controlling anisotropic hardening and $\beta$ is the second order non dimensional deviatoric tensor that describes anisotropy.

The Anisotropic Subloading Surface Model (ASSM) was implemented in the program FLAC to reproduce the same tests. This is an advanced constitutive model that requires a great number of constants and initial values (the same as the SSM and an additional four).

So, in order to obtain these model constants and initial values that best fit the laboratory test curves of the core material, a genetic algorithm was used (Pereira et al., 2014).

Figure 5 and Figure 6 compare the results obtained in the triaxial tests and in the $\mathrm{K}_{0}$ consolidation test, with those obtained by mathematical modeling using the ASSM. The figures show, respectively, the deviatoric stress invariant versus the axial deformation and the effective stress paths.

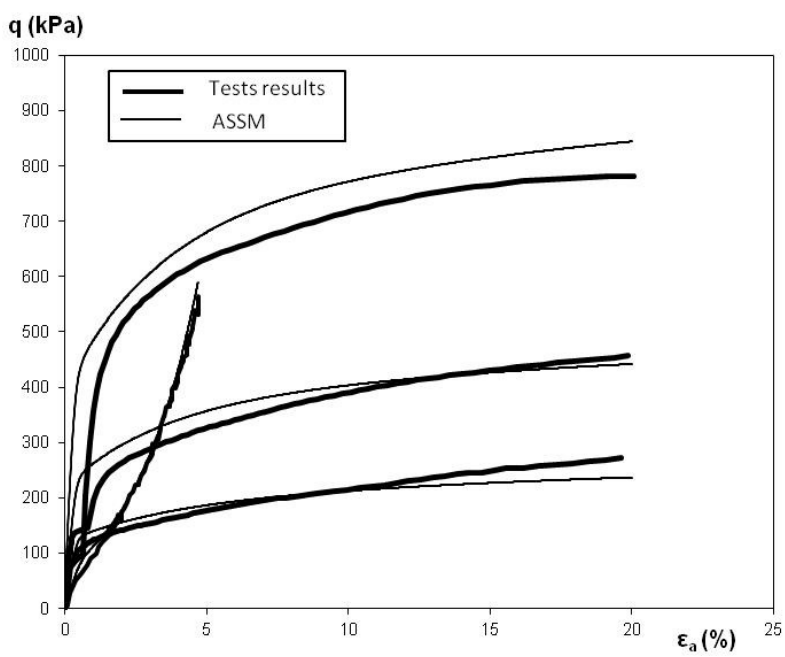

Figure 5. Deviatoric stress invariant versus the axial strain for the experimental results and the ASSM. The undrained triaxial tests with 200, 400 and $800 \mathrm{kPa}$ isotropic consolidation, and the $\mathrm{K}_{0}$ test are represented.

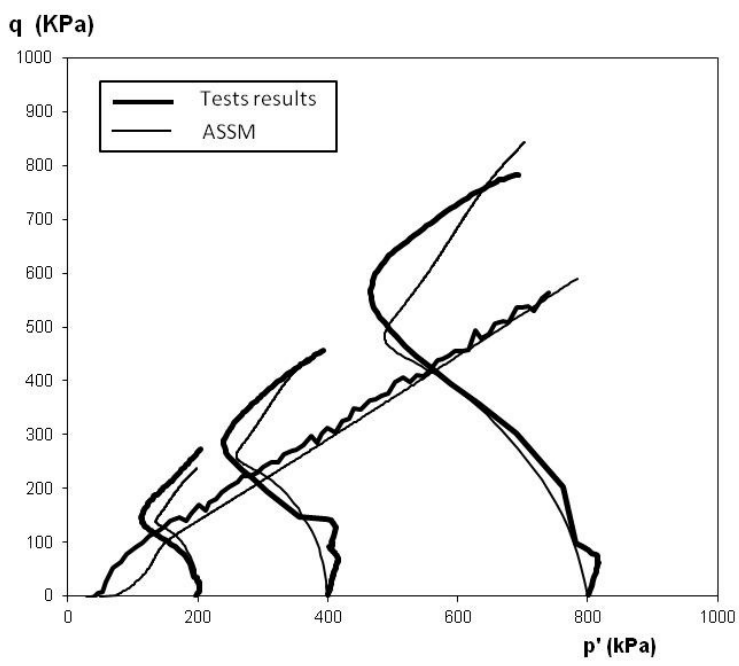

Figure 6. Effective stress paths for the test results and the ASSM. The undrained triaxial tests with 200,400 and $800 \mathrm{kPa}$ isotropic consolidation, and the $\mathrm{K}_{0}$ test are represented.
From the figures it's possible to conclude that the ASSM is not only able to reproduce adequately the triaxial stress paths, even when a reversal in their direction occurs, but is also able to reproduce the $\mathrm{K}_{0}$ consolidation line.

Significant plastic anisotropy both initial, $\eta_{a}=0.511$, and induced, $\mu_{a}=58.8$, were necessary to reproduce the experimental results.

The soil models used, including the ASSM, were incapable of reproducing the response of the shells' materials (soil-rockfill mixture) under undrained triaxial compression conditions for the three different isotropic consolidation stress levels (200, 400 and $800 \mathrm{kPa}$ ). This is most probably due to the well known property of rockfill materials: their shear strength increases sublinearly with the effective mean stress. In other words the critical state line is not a straight line, its slope decreases with effective mean stress.

\section{ODELOUCA DAM CONSTRUCTION: NUMERICAL ANALYSIS}

\subsection{Geometry discretization and material model constants}

A finite element mesh comprising 5241 elements was used to simulate Odelouca dam construction under plane strain conditions (see Figure 7).

The dam's numerical analyses were performed in terms of effective stress, assuming the materials as saturated but with different fluid (Biot) moduli, to account for non saturation and its implications in pore pressure generation. The initial effective stress and the size of the yield surface due to the material compaction process must also be specified.

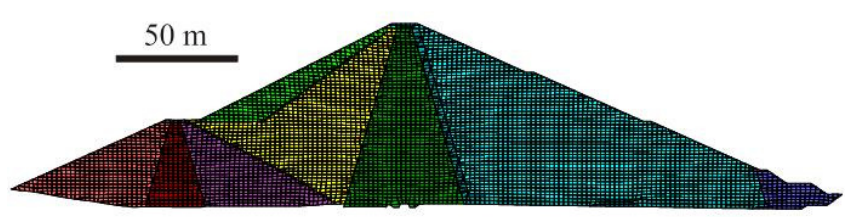

Figure 7. Odelouca's dam mesh.

This was the first numerical analysis performed using the monitoring results obtained from Odelouca Dam. Two models (MCCM and the SSM) were used in order to compare the results. The analysis presented here is a back analysis in that the results obtained from the monitoring of the construction are already available, but it relies, as much as possible, on the use of material model constants determined from the laboratory tests performed on the materials of the dam. 
The material model constants adopted are presented in Table 1 for both models. These constants were determined from the laboratory tests carried out during the construction of the dam.

The construction of the dam is simulated by the sequential activation of elements in 60 horizontal layers, approximately $1.3 \mathrm{~m}$ thick, from the foundation to the crest. In order to be able to compare the computed with the measured settlements, the displacements of the nodes belonging exclusively to the newly placed layer, resulting from the loading stage where the layer is activated, are ignored.

\subsection{Results of the analysis}

Figure 8 and Figure 9 present, respectively, the total vertical stress at elevation $19 \mathrm{~m}$ (from the foundation) and the total vertical stress field of the tallest cross-section of Odelouca dam. The SSM produces a greater transfer of load from the core to the shoulders.

Table 1. Odelouca dam material parameters.

\begin{tabular}{cccccc}
\hline Material & Core & $\begin{array}{c}\text { Shoul- } \\
\text { ders }\end{array}$ & $\begin{array}{c}\text { Upstream } \\
\text { shell } \\
\text { rockfill }\end{array}$ & Filter & $\begin{array}{c}\text { Toe } \\
\text { drain } \\
\text { rockfill }\end{array}$ \\
\hline$\lambda$ & 0.10 & 0.04 & 0.053 & 0.05 & 0.01 \\
$k$ & 0.03 & 0.006 & 0.01 & 0.005 & 0.002 \\
$M$ & 1.25 & 1.60 & 1.60 & 1.60 & 2.00 \\
$\nu$ & 0.43 & 0.37 & 0.25 & 0.2 & 0.30 \\
$\mathrm{~N}$ & 1.88 & 1.51 & 2.00 & 1.60 & 2.00 \\
$\rho$ & 1.325 & 1.553 & 1.78 & 1.40 & 1.70 \\
$\left(\mathrm{Mg} / \mathrm{m}^{3}\right)$ & & & & & \\
$\lambda^{*}$ & 0.035 & 0.028 & 0.085 & 0.02 & 0.085 \\
$k^{*}$ & 0.003 & 0.006 & 0.022 & 0.002 & 0.022 \\
$u$ & 7.41 & 18.43 & 30.00 & 10.00 & 30.00 \\
$p_{c 0}(\mathrm{kPa})$ & 385.7 & 303.7 & 300.0 & 500.0 & 800.0 \\
\hline & & & & & \\
\hline
\end{tabular}

In Figure 10 it is possible to see the measured and computed settlement profiles along a vertical line crossing the crest on the tallest cross-section of Odelouca dam.

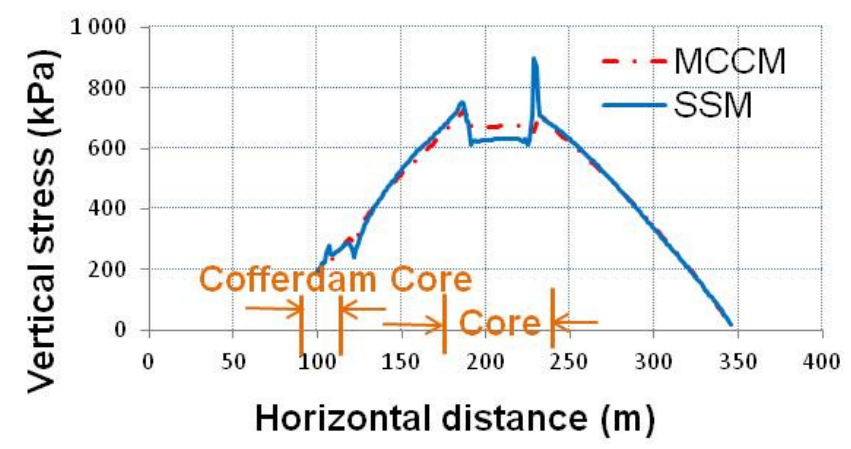

Figure 8. Total vertical stress at elevation $19 \mathrm{~m}$.

Figure 11 represents the settlement field at the same cross-section. The higher settlement obtained is about $0.4 \mathrm{~m}$ and $0.8 \mathrm{~m}$, respectively for the MCCM and for the SSM (and occurs between eleva- tion 40 and $50 \mathrm{~m}$ in the core of the dam). However, the higher settlement measured in the dam is about $1 \mathrm{~m}$ (approximately $1.3 \%$ and of the dam height). So, none of the models were able to reproduce the behaviour observed in the dam. This is probably because these models were incapable of conveniently describing the experimental results for both materials (core and shell's). Also, these two models used a circular deviatoric cross section for the yield surface which produces fewer settlements.

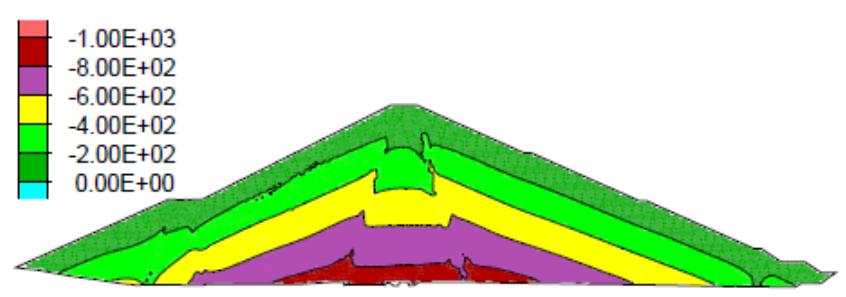

a)

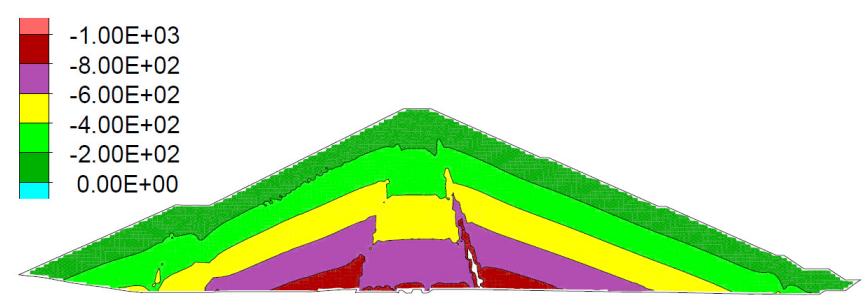

b)

Figure 9. Total vertical stress field in the tallest Odelouca dam cross-section: a) MCCM and $b$ ) SSM

The next step in the numerical modeling of Odelouca Dam will involve the use of a model that introduces the plastic anisotropic behaviour of the materials with a non-circular deviation cross section for the yield surface.

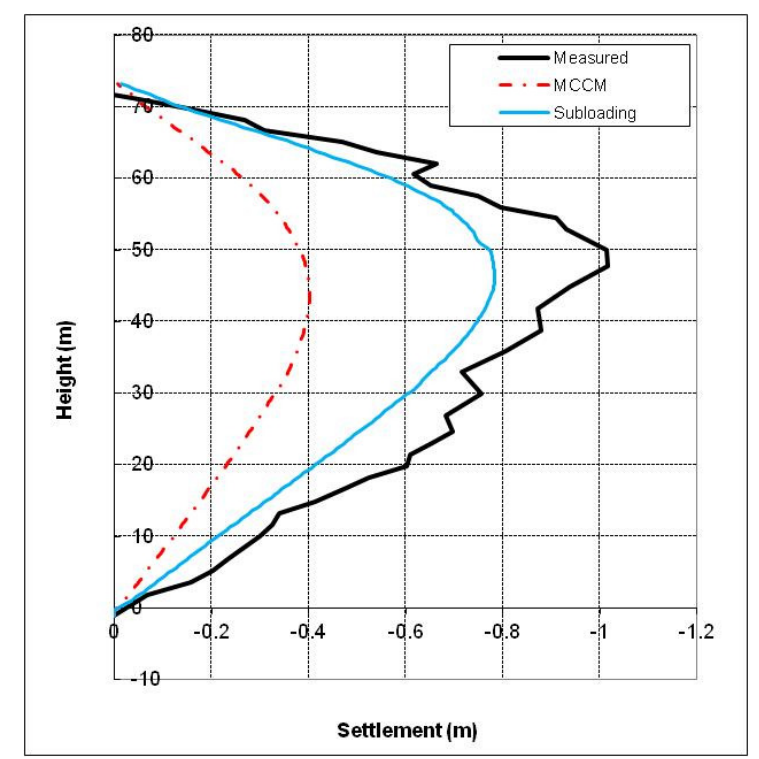

Figure 10 . Settlement profile at end of construction along a vertical line on the tallest cross section of Odelouca's dam. 


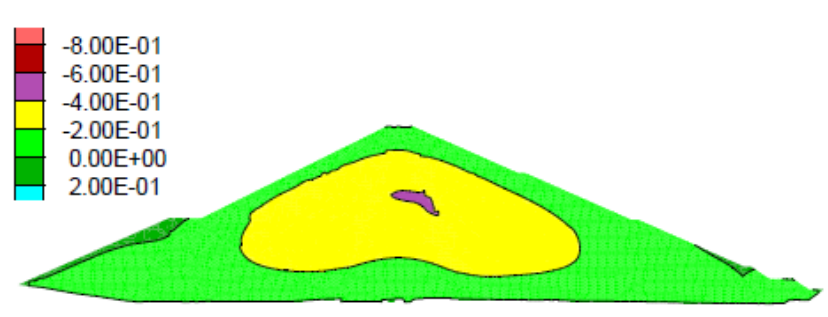

a)

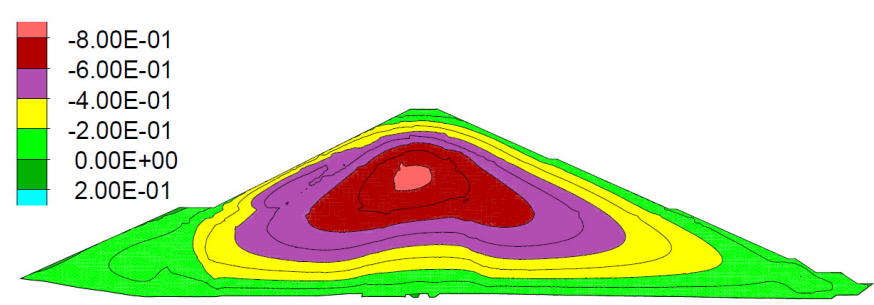

b)

Figure 11. Settlements in the tallest Odelouca dam crosssection: a) MCCM and b) SSM.

\section{CONCLUSIONS}

In this paper the results of a numerical analysis of Odelouca dam's construction are presented together with the numerical modelling of some of the $\mathrm{K}_{0}$ consolidation and the undrained triaxial tests performed on the core material. These analyses used the explicit finite difference program FLAC.

Test results were compared between the Modified Cam Clay Model (existing in the software) with those obtained with a non-conventional elastoplastic model, the Subloading Surface Model, which predicts a gradual transition between the elastic to elastoplastic behaviour, for the core material placed in the dam. They were also compared with those obtained with the Anisotropic Subloading Surface Model. The only model that was capable of fitting both the triaxial and the $\mathrm{K}_{0}$ consolidation tests was the Anisotropic Subloading Surface Model.

The soil models used, including the ASSM, were incapable of reproducing the response of the shells' materials (soil-rockfill mixture) under undrained triaxial compression conditions for the three different isotropic consolidation stress levels (200, 400 and $800 \mathrm{kPa}$ ). This is most probably due to the well known property of rockfill materials: their shear strength increases sublinearly with the effective mean stress. In other words the critical state line is not a straight line, its slope decreases with effective mean stress.

The results obtained from the numerical analysis of Odelouca dam's construction using both models (MCCM and SSM) presented less settlements then the measurements obtained with the observation equipment installed. Also, these models were not able to reproduce well all the laboratory test results from the dam materials.
One future development is related to the improvement of the model in order to better fit the experimental results obtained for the shell's material under different stress paths.

Other future developments include the use of more sophisticated models such as the Anisotropic Subloading Surface Model, which was able to reproduce reasonably well the undrained triaxial tests and the $\mathrm{K} 0$ consolidation test, on the numerical analysis of the dam. There is also the intention of improving the method to determine the initial size of the yield surface and the initial effective stress from the matric suction using the water retention curve of the material together with the knowledge of the water content.

\section{ACKNOWLEDGEMENTS}

The authors would like to thanks the owner of Odelouca dam, Águas do Algarve, SA, for the availability of materials to the tests. We would like also to express gratitude to the LNEC technicians for their contribution to the experimental work.

\section{REFERENCES}

Davies, M. C. R. \& Newson, T. A. 1993 A critical state constitutive model for anisotropic soil. Proc. of the Wroth Memorial Symposium held at St. Catherine's College, Oxford, $27^{\text {th }}-29^{\text {th }}$ July, 1992, pp. 219-229, London, 1993. Thomas Telford

Hashiguchi, K. 1989. Subloading surface model in unconventional plasticit., Int. J. Solids Struct. 25. No.8, pp. 917-945.

Maranha, J. R. 1997. Analysis of embankment dams: computational aspects. PhD Thesis, University of Wales, Swansea.

Pereira, C., Maranha, J. R. \& Brito, A. 2014. Advanced constitutive model calibration using genetic algorithms: some aspects. $8^{\text {th }}$ European Conference on numerical Methods in Geotechnical Engineering, 18-20 June, Delft, The Netherlands.

Roscoe, K. \& Burland, J. B. 1968. On the generalized stress strain behaviour of wet clay. Engineering Plasticity, eds, Cambridge, England: Cambridge University Press., J.Heyman and F.A. Leckie, pp. 535-609.

Schofield \& P. Wroth. 1968. Critical State Soil Mechanics. McGraw-Hill. Londres.

Wong, P. K. K. \& P. Mitchell, R. J. 1975. Yielding and plastic flow of sensitive cemented clays. Géotechnique, 25(4): 763$782,1975$. 